\title{
A Balloon-Assisted Gliding UAV for Aerosol Observation in Antarctica*
}

\author{
By Shin-Ichiro HIGASHINO, ${ }^{1)}$ Masahiko HAYASHI, ${ }^{2)}$ Shuji NAGASAKI, ${ }^{1)}$ Shiina UMEMOTO, ${ }^{3)}$ \\ and Motoki NISHIMURA ${ }^{4}{ }^{\dagger}$ \\ ${ }^{1)}$ Department of Aeronautics and Astronautics, Kyushu University, Fukuoka, Japan \\ ${ }^{2)}$ Department of Earth System Science, Fukuoka University, Fukuoka, Japan \\ ${ }^{3)}$ Graduate School, Fukuoka University, Fukuoka, Japan \\ 4) Graduate School, Kyushu University, Fukuoka, Japan
}

(Received January 27th, 2014)

\begin{abstract}
A novel aerosol observation and sampling system using a combination of a balloon and a UAV is developed in order to retrieve observation apparatuses and aerosol samples easily at low cost. Observation apparatuses are installed on a motor-glider UAV named Phoenix, and the apparatuses conduct observation and sampling during ascent of the Phoenix suspended by a free balloon. The Phoenix is automatically separated from the balloon at a target altitude, returns to the ground station by gliding automatically, and it is retrieved with the use of a parachute. Four sets of this system were prepared and brought to Syowa Station which is one of the Japanese Antarctic Stations by the first- and the fourth-named authors as summer team members of the 54th Japanese Antarctic Research Expedition (JARE54) in December 2012. Five observation flights were conducted in January 2013 using Phoenix-03. Aerosol observation and sampling in the five flights were successfully performed up to $10,000 \mathrm{~m}$ in altitude. Details of the Phoenix and flight results are described in this paper.
\end{abstract}

Key Words: UAVs, Aerosol Observation, Antarctica, Free Balloon

\section{Introduction}

Aerosols including the so called PM2.5 are very small particles drifting everywhere in the Earth's atmosphere. The circulation of materials in the atmosphere is clarified by observing aerosol density and size, and by analyzing chemical composition of them which differs depending on the location and altitude. Understanding the circulation of materials in the atmosphere not only helps in prediction of the future state of several environmental issues such as atmospheric pollution and global warming, but can also provide clues to overcome these issues. Therefore, many meteorological agencies, institutes and universities are performing aerosol observation at various global locations including Antarctica.

Captive balloons, free balloons and manned airplanes are usually used for the density observation of aerosols. The free balloon method is handy and inexpensive while it can easily reach higher altitude more than $20 \mathrm{~km}$ till the balloon breaks up. However, retrieval of the observation apparatuses which cost more than US\$10,000/unit is often difficult, and they are unavoidably discarded every time. The number of observations is accordingly limited due to the budget limit. Especially in the case of aerosol sampling, not being able to retrieve apparatuses is fatal and meaningless; therefore, the free balloon method is not suitable for aerosol sampling.

(C) 2014 The Japan Society for Aeronautical and Space Sciences.

* Presented at the 2013 Asia-Pacific International Symposium on Aerospace Technology (APISAT-2013), Nov. 20-22, 2013, Takamatsu, Japan

† Currently Toyota Motor Corporation
Unmanned aerial vehicles (UAVs) are useful and cost-effective tools for various scientific observations, and several attempts using UAVs have been made including in the polar regions. ${ }^{1-5)}$ UAVs can also be used for aerosol observation and sampling, but the capability to climb up to the altitude of at least the lower layer of the stratosphere is required for scientific reasons, and it is not usually easy for a small UAV to climb up to such a high altitude.

In order to solve this problem, the authors came up with an idea which combines a balloon and an UAV. In this system, observation apparatuses are installed in the UAV which is suspended from the balloon. The apparatuses measure aerosol density and collect samples while the balloon-UAV system climbs up. After reaching a target altitude, the UAV is separated from the balloon and return to the launch point on the ground automatically.

With the aim of operating such a system at Syowa Station, one of the Japanese Antarctic stations, in Antarctic summer in 2013, we started the basic study in 2008 by developing the UAV and performing domestic flight tests. Four sets of the system were taken to Syowa Station by the Japanese icebreaker "Shirase" in December 2012, and five observation flights were conducted in January 2013. In this paper, details of the system and the results of the operation at Syowa Station are described.

\section{Synopsis of the Observation System}

\subsection{Observation method}




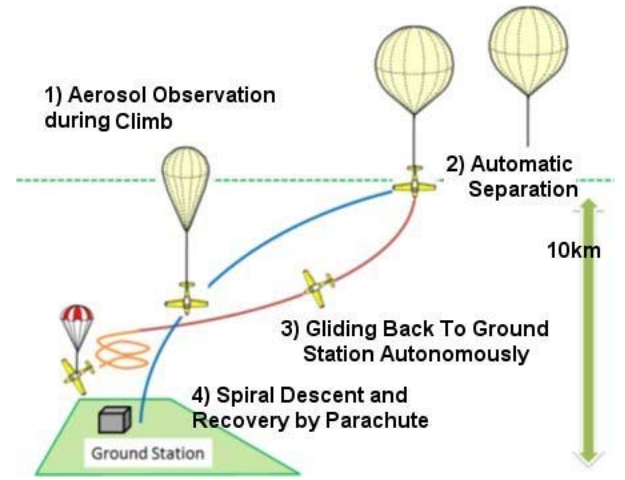

Fig. 1. Mission profile of aerosol observation and UAV recovery.

The observation system is composed of a balloon and an UAV suspended from a balloon with its nose down. The procedure of aerosol observation, sampling and recovery is shown in Fig. 1.

Aerosol observation apparatuses are installed in the UAV. An optical particle counter (OPC) measures aerosol density and size, and an aerosol sampler (impactor) collects samples during the climb as shown in 1) in Fig.1. The observation and sampling continue up to a target altitude of approximately $10 \mathrm{~km}$ which is the typical altitude of the lower layer of the stratosphere in Antarctica. After reaching the target altitude, the UAV separates from the balloon automatically as shown in 2) in Fig. 1. The horizontal distance between the launch point and the separation point changes depending on the wind speed and direction during the climb. As the speed of the UAV builds up after separation, it pulls up its nose and starts gliding back to the launch point where the ground station is located as shown in 3) in Fig. 1. Aerosol observation is not performed during gliding because it is difficult to correct for the effect of airspeed of the UAV on observed aerosol density. Upon arrival above the ground station, the UAV spirals down towards the ground. It deploys a parachute at an appropriate altitude and lands on sea ice as shown in 4) in Fig. 1.

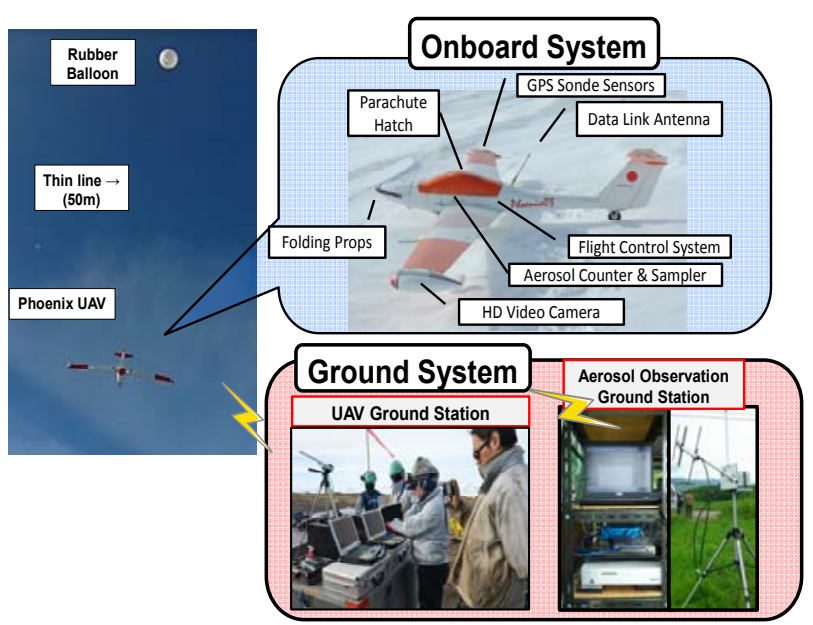

Fig. 2. Phoenix-03 and ground stations.

\subsection{Phoenix UAV}

The UAV developed for this mission is a motor-glider UAV named "Phoenix" with a foldable propeller and an electric motor as shown in Figure 2. The specifications of Phoenix are shown in Table 1.

All parts of Phoenix are made of glass fiber reinforced plastic (GFRP), and some of them are additionally reinforced by carbon fiber. The landing gear is made of aluminum for touchdown shock absorption of parachute landing. If a runway is available, it can also take off and land using wheels or skis by manual control. A parachute is stowed in the canopy, and the area of the parachute is determined so that the descending speed becomes approximately $5 \mathrm{~m} / \mathrm{s}$ at sea level. Although the parachute recovery can be done either manually or automatically, manual deployment is usually used because the UAV has to be guided to a suitable place for parachute landing on sea ice to avoid tide cracks and melted surface of sea ice. Phoenix returns to the launch point basically by gliding after separated from the balloon. It can use propulsive power of an electric motor with a foldable propeller for approximately 5 minutes in the case that the UAV cannot return to the station only by gliding.

Table 1. Specifications of Phoenix.

\begin{tabular}{|l|c|}
\hline Wing span & $2.9[\mathrm{~m}]$ \\
\hline Total weight & $10.0[\mathrm{~kg}]$ \\
\hline Payload weight & $2.0[\mathrm{~kg}]$ \\
\hline Wing area & $0.68\left[\mathrm{~m}^{2}\right]$ \\
\hline Maximum L/D ratio & 20 \\
\hline Maximum airspeed & $40[\mathrm{~m} / \mathrm{s}$ EAS $]$ \\
\hline Power plant & Electric motor \\
\hline Powered flight time & $5[\mathrm{minutes}]$ \\
\hline
\end{tabular}

The flight control system hardware for Phoenix named "AP-CUB" was developed originally for another UAV project assuming the operation at low altitude in the Antarctic summer. ${ }^{6,7)}$ The AP-CUB is composed of two microprocessors (Renesas H8S-2638, $20 \mathrm{MHz}$ ), a compact GPS receiver, and several MEMS sensors such as a differential pressure sensor, an absolute pressure sensor, 3-axis rate gyros, 3-axis accelerometers and a GPS receiver. One microprocessor is mounted on a single $3 \mathrm{~cm}$ x $9 \mathrm{~cm}$ PCB with peripheral circuits and a DC/DC converter, and All MEMS sensors are also mounted on another single PCB of the same size with anti-aliasing filters for $\mathrm{A} / \mathrm{D}$ conversion. An $\mathrm{RC}$ receiver is connected to the AP-CUB, and the driving signal of the servo motors can be switched between RC manual control and computed output of the microprocessors. All electric power for avionics is supplied by Ni-MH batteries, and electric power for the motor is provided by Li-Po batteries.

All parts of the AP-CUB are selected so that it works at low temperature down to $-25{ }^{\circ} \mathrm{C}$, but the typical lowest air temperature around the tropopause above Syowa Station in Antarctica is less than $-60{ }^{\circ} \mathrm{C}$. It is also well 


\section{S. HigASHINO et al.: A Balloon-Assisted Gliding UAV for Aerosol Observation in Antarctica}

known that batteries do not last long at low temperature. Therefore, most of the devices including the AP-CUB, servo motors and batteries are thermally insulated using thin styrene foam plates covered by aluminum-coated polyester film known as a survival sheet or an emergency sheet as shown in Fig. 3.

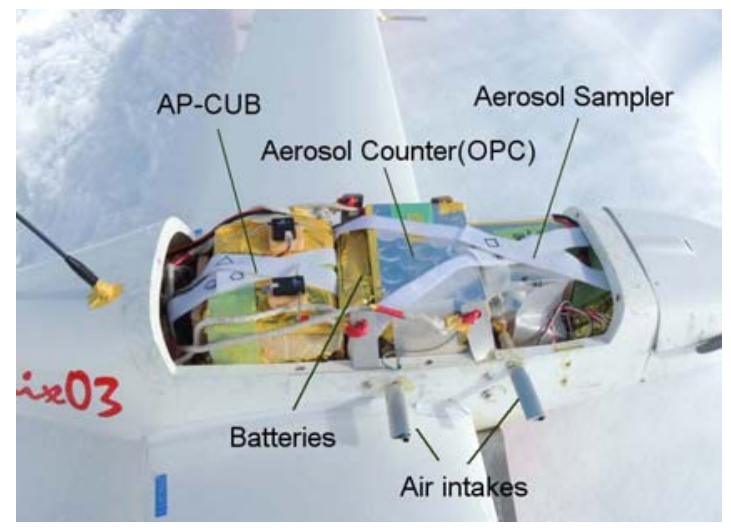

Fig. 3. Thermally insulated AP-CUB mounted in the fuselage.

Approximately two cylinders of helium gas, $14 \mathrm{~m}^{3}$, are required for the launch of the whole system. Phoenix is suspended from the balloon using a 50 m-long connecting line for avoiding the contamination to aerosol observation caused by the balloon. The connecting line is a very thin string made of Dyneema or ultra high molecular weight polyethylene (UHMWPE), and the string is cut by heat wire at the specified altitude automatically. Heat wire is installed at the outside belly of the UAV and covered by a fairing.

Aerosol observation apparatuses are installed in the fuselage as shown in Fig. 3. Two air intakes for the aerosol sampler and counter respectively are mounted through the right side wall of the fuselage with airfoil-shaped covers. A meteorological observation sensor module using a so-called GPS-sonde is mounted at the right tip of the wing with a fairing, and a HD video camera is also mounted at the left tip of the wing with the same fairing as shown in Fig. 2.

Flight data are recorded in a SD card, and also transmitted to the ground station (Laptop PC) using a 2.4 $\mathrm{GHz}$ wireless communication link. After arrival above the ground station, the UAV spirals down towards the ground. Four waypoints are specified prior to the flight for the spiral descent by the ground station. After separation from the balloon, the UAV heads for the specified waypoint.

Aerosol density data and meteorological observation data using a so-called radio-sonde apparatus are transmitted to the observation ground station (another laptop PC) using a $400 \mathrm{MHz}$ wireless communication link which is usually used for a radio-sonde observation system.

\section{Feasibility study and low temperature effect}

\subsection{Feasibility study by point mass simulation}

Although the UAV is equipped with a propulsion system, it is desirable to glide back to the launch point without using power in order to reduce battery weight. Whether or not the UAV can glide back to the launch point depends on the wind profile. A Simulation is performed using a point mass model with lift and drag characteristics obtained by a wind tunnel test and wind observation data at Syowa Station for the past three years. ${ }^{8)}$ Airspeed is assumed to be controlled to the so-called best glide speed in wind which gives the shallowest gliding angle for the specific wind speed and direction. The best glide speed in wind is calculated from the basic $L / D$ characteristics and the wind speed and direction at the corresponding altitude. The course is assumed to be controlled so that the ground speed vector is directed at the launch point on the ground. The bank angle is assumed to change instantaneously.

Figure 4 shows the horizontal wind speed profile of 365 days observed over Syowa Station by weather balloons in $2010 .^{8)}$ Different colors of the lines indicate different days. The lateral axis is true wind speed and longitudinal axis is altitude. It shows that significant increase in wind speed due to so called "Katabatic wind" at lower altitude less than 1,000 to $2,000 \mathrm{~m}$ is observed.

The simulation results based on the wind data that assumes that the UAV climbs up at $5 \mathrm{~m} / \mathrm{s}$ after launch, drifts away from the launch point by wind, and separates from the balloon at $9,000 \mathrm{~m}$ are shown in Fig.5. The

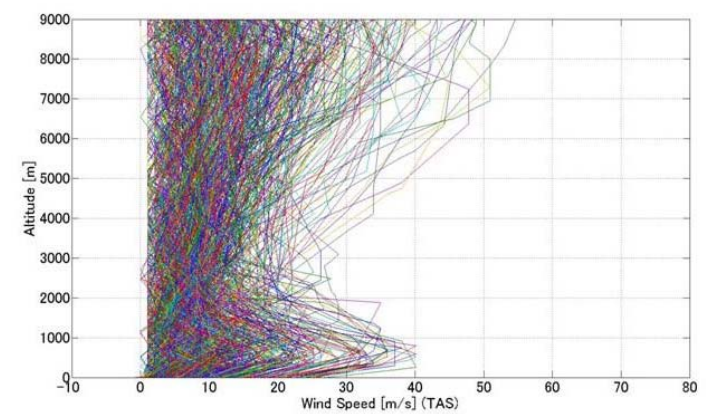

Fig. 4. Wind speed profile observed over Syowa Station in 2010.

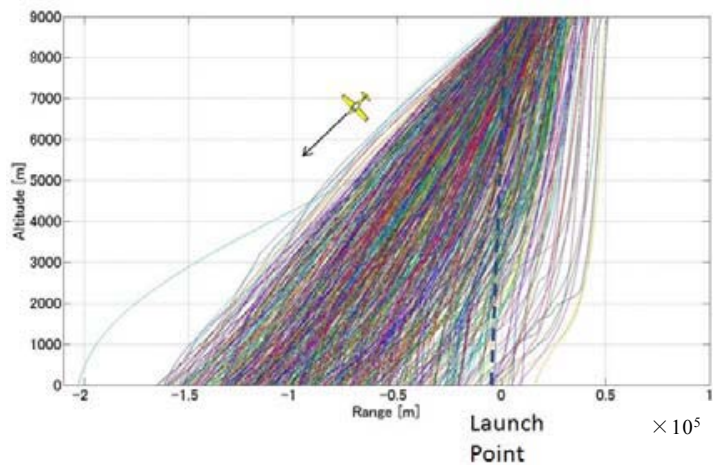

Fig. 5. Gliding simulation with the separation altitude at $9000 \mathrm{~m}$ using observed wind data over Syowa Station in 2010. 
lateral axis is the distance from the launch point and the longitudinal axis is altitude. If the flight track passes across the vertical blue broken line at range $0 \mathrm{~m}$, it means the UAV successfully glides back over the launch point. Most of the flight tracks pass over the launch point with positive altitude margins, and it is found that the number of flights which cannot reach back to the launch point is less than $10 \%$. The success rate is almost the same in 2011 and 2012.

Figure 6 shows the relationship between the average wind speed and the remaining altitude when the UAV arrives just over the launch point. Blue dots indicate the cases when the wind speed on the ground is less than 5 $\mathrm{m} / \mathrm{s}$ and the launch is possible, and red dots indicate the cases when the launch is impossible due to strong surface wind. Figure 6 shows that possibility of return does not seem to heavily depend on the wind speed on the ground; rather, returning becomes difficult when the average wind speed exceeds approximately $20 \mathrm{~m} / \mathrm{s}$. This information is useful for the operation in Antarctica.

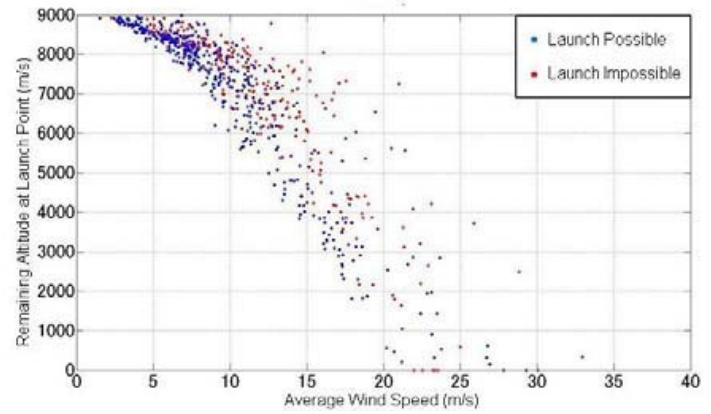

Fig. 6. Relationship between average wind speed and remaining altitude at the launch point.

\subsection{Low temperature effect on control}

The minimum air temperature around the tropopause over Syowa Station in January is typically $-60{ }^{\circ} \mathrm{C}$ or less as shown in Figure 7. January is the month when the operation in summer expedition is planned.

The function of the avionics, batteries and all moving parts of the Phoenix except for the electric propulsion system are tested in a freezer. The avionics, servo motors

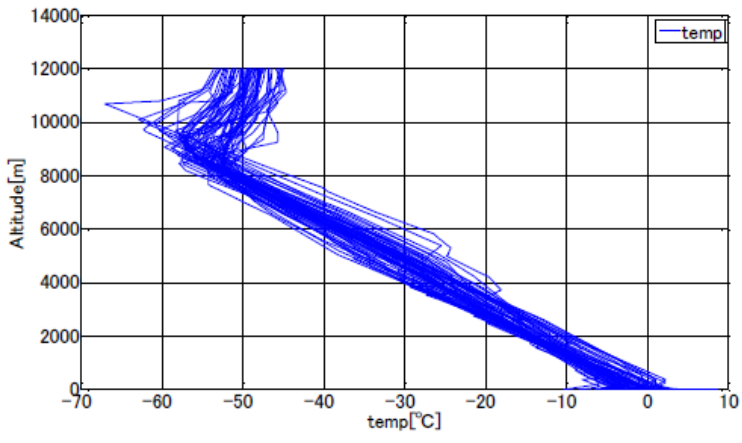

Fig. 7. Relationship between air temperature and altitude up to $12 \mathrm{~km}$ over Syowa Station for 31 days in January 2010. ${ }^{8)}$ and batteries are thermally insulated as mentioned earlier. The test is conducted for three hours at one time while changing air temperature so that the time versus air temperature profile simulates the real mission. The servo motors are driven using the recorded flight data in lowaltitude flight tests in order to simulate electric current consumption.

Figure 8 shows one of the test results. No major problems are found even at $-60{ }^{\circ} \mathrm{C}$ of air temperature except for the movement delay of the servo motors. Low air pressure tests corresponding to $12 \mathrm{~km}$ in altitude are also conducted, and no major problems are found.

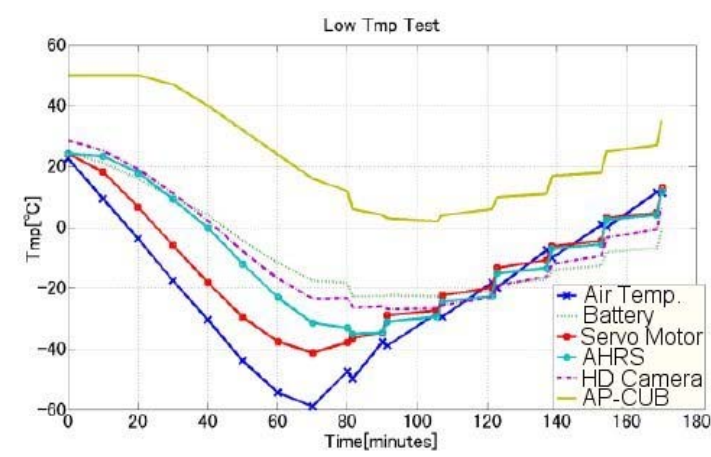

Fig. 8. One of the results of low temperature test of avionics, batteries, and servo motors.

Phoenix UAV is controlled so that its Equivalent Air Speed (EAS) follows the command, and its course follows the line connecting the waypoints which include the separation point. ${ }^{9)}$ Since the movement delay of the servo motor is observed even with thermal insulation, the effect of delay together with air density to the control performance is evaluated using a 6-DOF rigid body simulator with PID controllers. ${ }^{9)}$ Delay parameters of the servo motor are identified using the low-temperature tests.

Figure 9 shows the simulated response to the unit step EAS command in three different altitudes. The effect of time delay of the servo motor and air density which change depending on temperature and flight altitude is included in the simulation model. Slight degradation in damping and settling time is observed as the altitude increases, but the differences are confirmed to be small.

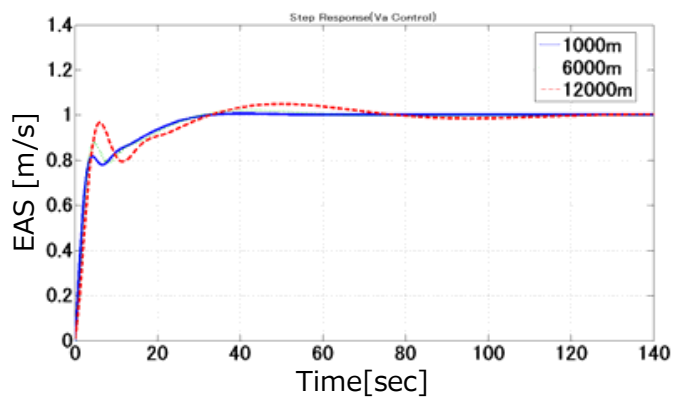

Fig. 9. Simulated response of EAS to unit step EAS command. 


\section{S. Higashino et al.: A Balloon-Assisted Gliding UAV for Aerosol Observation in Antarctica}

\section{Aerosol Observation Flights at Syowa Station}

After conducting several domestic flight tests in which the separation altitude was low $(1,000 \mathrm{~m}$ to $2,000 \mathrm{~m})$, the first- and fourth-named authors left Japan in November 2012 as the members of the summer team of 54th Japanese Antarctic Research Expedition (JARE54) with four sets of Phoenix, 20 cylinders of helium gas for ten flights and other peripheral goods. After getting close to Syowa

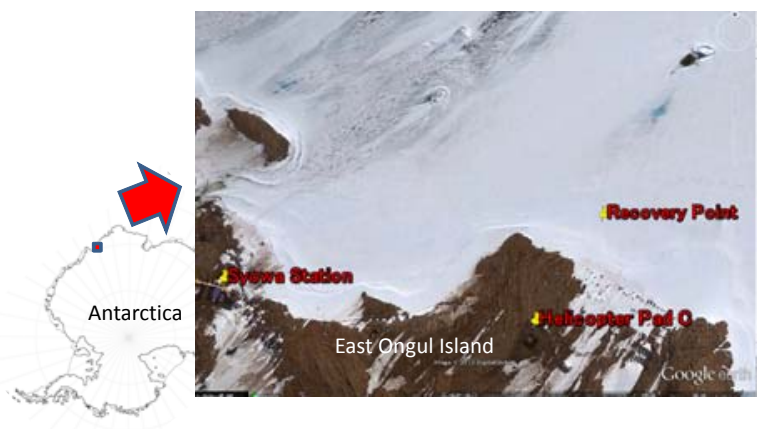

Fig. 10. Location of Syowa Station, launch and recovery point.

Station (Fig. 10) via the icebreaker "Shirase," we were transported to the Station via a helicopter.

Observation flights were conducted five times in January $2013 \quad$ using Phoenix-03. The major factors affecting go/no-go decision making were the surface wind speed and direction. The wind forecast of the upper air ${ }^{10}$ and balloon trajectory prediction $^{11)}$ were also quite helpful. Another factor to consider was the interference with other operations especially the ones using helicopters for safety reasons. The Phoenix-03 was launched from one of the helicopter pads by the cooperation of other expedition team members after

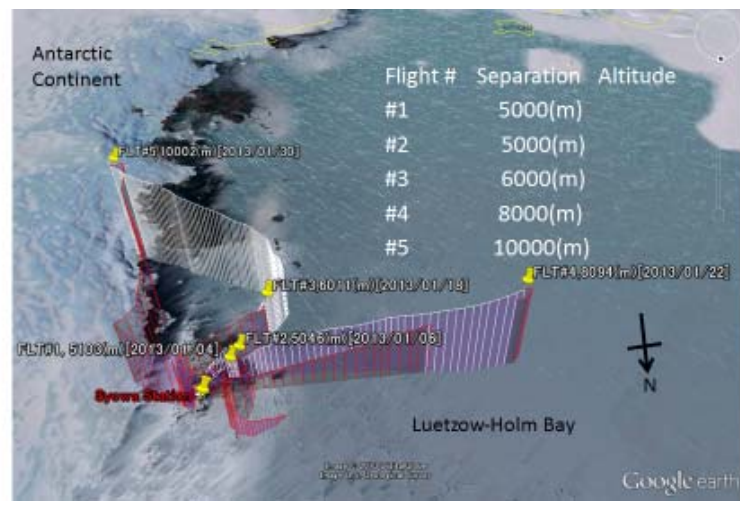

Fig. 12. Ascent and gliding tracks of five observations. helicopter operation had finished in the evening as shown in Fig. 11.

Separation altitude was planned to increase step by step from 5,000m (flight $\# 1$ and flight \#2) to $6,000 \mathrm{~m}$ (flight \#3), 8,000m (flight \#4) and 10,000m (flight \#5). Ascent tracks and gliding tracks of all five flights looking from the north are shown in Fig. 12. Yellow pins indicate the separation points, white lines indicate ascent tracks, and red lines indicate gliding tracks with perpendicular lines to the ground respectively for clarity. Aerosol observation and sampling were conducted as planned in all flights. The maximum separation altitude was $10 \mathrm{~km}$ in flight \#5.

In flight $\# 1$, the parachute unintentionally deployed during the pull-up maneuver just after separation from the balloon at $5,000 \mathrm{~m}$ altitude. The cause was the loss of GPS signal during the pull-up maneuver, and the automatic emergency parachute deployment procedure worked. However, aerosol observation and sampling were performed as planned during ascent, and Phoenix-03 landed on sea ice with the use of a parachute approximately $5 \mathrm{~km}$ off the west coast of the Ongul Islands and was retrieved by a helicopter. It was found that the lost GPS signal during the pull-up maneuver was recovered after the pull-up, and the flight software was modified after flight \#1 so that it ignores the loss of GPS signal and controls its yaw rate as zero when the GPS signal is lost. It was also found that the loss of the GPS signal during the pull-up occurred in almost all other flights and even in the ascent phase. It may be caused by the rapid rotation of the UAV while it is suspended by the balloon, and/or singular satellite positioning around the polar region, but the true cause has not been clarified yet.

Time histories of equivalent airspeed (EAS) and its command, GPS altitude, ground speed (GS) and true airspeed (TAS), and the number of GPS satellites in view in flights \#4 and \#5 are shown in Figs. 13 and 14 respectively.

In Fig. 13, separation from the balloon occurred at $8,000 \mathrm{~m}$ in altitude, after approximately $3500 \mathrm{sec}$. in time. The number of GPS satellites in view at that time becomes zero, and it indicates the GPS signal was lost. The upper
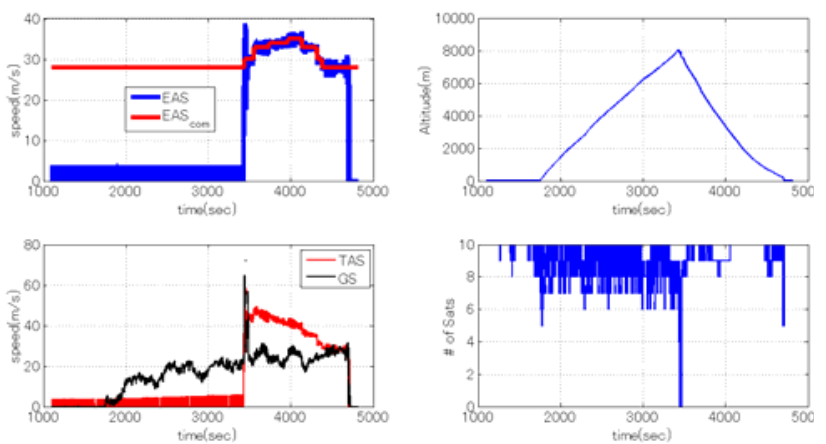

Fig. 13. Time history of EAS, GPS altitude, GS, TAS and number of GPS satellites in flight \#4. 

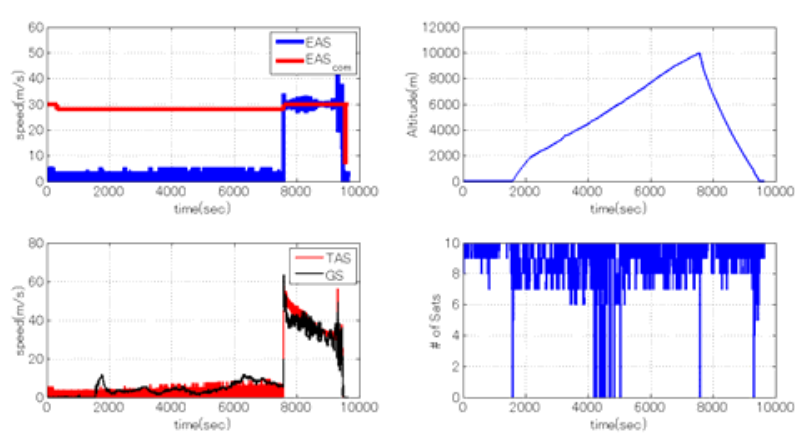

Fig. 14. Time history of EAS, GPS altitude, GS, TAS and number of GPS satellites in flight $\#$.

wind speed on that day was relatively high (20 to $25 \mathrm{~m} / \mathrm{s})$ which can be seen from the ground speed during ascent (black line in lower left plot). It can be seen from the figure that EAS (blue line in upper left plot) satisfactorily followed the command (red line).

As seen from the time history of the GPS altitude in Fig. 14 , the time to reach the separation altitude $(10,000 \mathrm{~m})$ is very long, to be more exact, approximately 1 hour and 40 minutes in this observation flight. The ascent speed decreases to approximately $1.6 \mathrm{~m} / \mathrm{s}$ after $2000 \mathrm{sec}$., and is considerably slow compared with the normal ascent speed $(5 \mathrm{~m} / \mathrm{s})$ before $2000 \mathrm{sec}$. and other flights. It is estimated that it was probably caused by the leak of helium gas from its valve attached to the balloon at around 2,000 sec. A GPS signal loss was observed not only at the time of separation, but also during ascent. Ground speed (GS) and True Air Speed (TAS) indicate that the wind speed of this flight is low.

Figure 15 shows the three-dimensional flight track of flight \#3 in which the separation altitude is $6,000 \mathrm{~m}$. Since the average upper wind speed in this flight was low, the horizontal distance between the separation point and the launch point is only about $7 \mathrm{~km}$. After arriving at the space over the launch point, Phoenix-03 descended by spiraling down to the ground and passing by four waypoints set over the launch point.

Figure 16 shows the three-dimensional flight track of flight \#4 in which the separation altitude is $8,000 \mathrm{~m}$. The

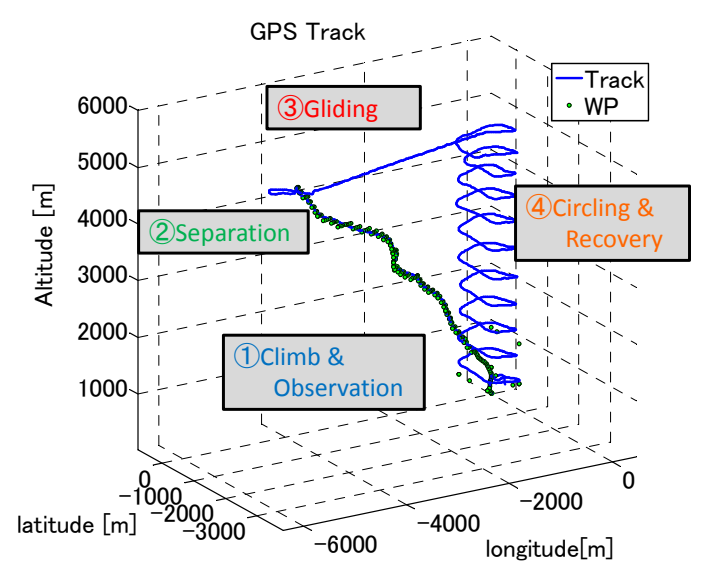

Fig. 15. Three dimensional flight track of flight \#3.

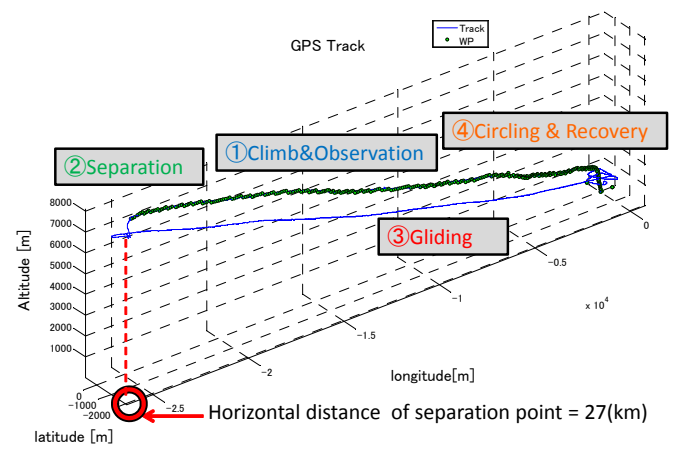

Fig. 16. Three dimensional flight track of flight $\# 4$.

average wind speed is relatively high, and the horizontal distance between the separation point and the launch point is about $27 \mathrm{~km}$. The remaining altitude over the launch point is $1,500 \mathrm{~m}$.

The Phoenix-03 was retrieved with the use of a parachute on sea ice hundreds of meters off the north coat of East Ongul Island where Syowa Station is located after the altitude was reduced to 100 to $200 \mathrm{~m}$ above sea ice as shown in Fig. 17.

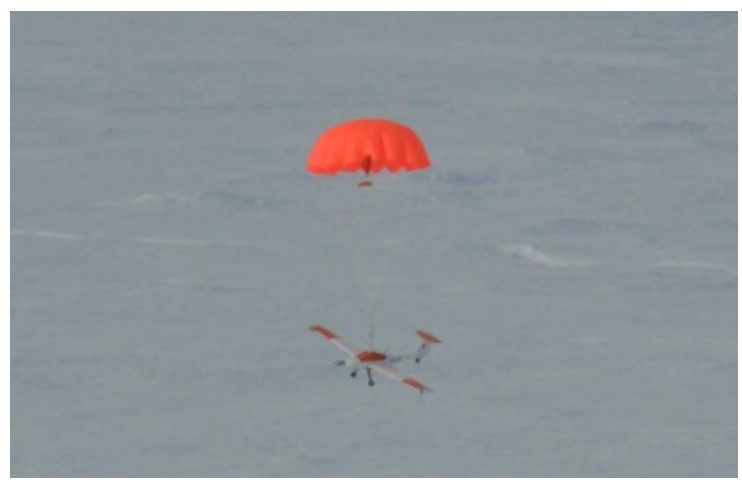

Fig. 17. Parachute recovery on sea ice.

The Phoenix is also equipped with a HD video camera. One shot from the video taken by the UAV just after pull-up at about 10,000 $\mathrm{m}$ in altitude is shown in Fig. 18.

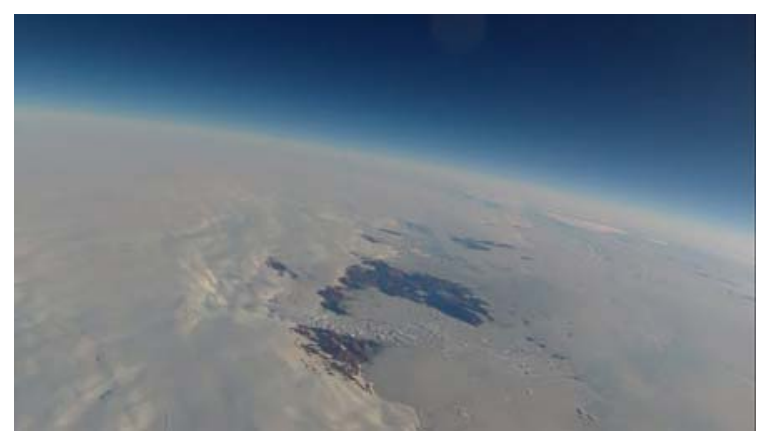

Fig. 18. Antarctic continent (left) and bare rock area along Soya Coast (center) taken from Phoenix-03 at 10,000 $\mathrm{m}$ in altitude

Figure 19 shows the vertical distribution of observed aerosol density in flight \#5. Detailed analysis is under progress. The obtained data seems normal compared with other observations using just a balloon, and the circulation of aerosol in Antarctica will be clarified using the 


\section{S. Higashino et al.: A Balloon-Assisted Gliding UAV for Aerosol Observation in Antarctica}

obtained samples.

The maximum altitude of aerosol observation using a manned airplane conducted in the past at Syowa Station was $8,000 \mathrm{~m}$. As far as we know, $10,000 \mathrm{~m}$ in altitude became the highest altitude record of aerosol observation

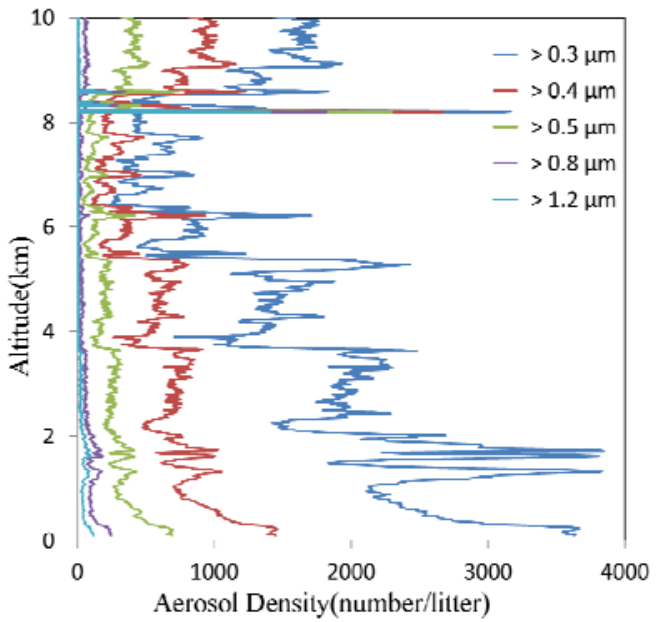

Fig. 19. Observed vertical distribution of aerosol density up to $10,000 \mathrm{~m}$ in altitude.

including manned and unmanned airplanes launched or taking off from Antarctica. Although Phoenix-03 was retrieved by helicopter at the first flight, no Phoenix and observation apparatuses were lost while conducting five observations in one month. The number of observations at Syowa Station per year is usually three to five times due to budget limitations, and the significance of five observations and sample returns without losing any observation apparatuses in only one month should be enhanced.

\section{Conclusions}

A novel aerosol observation and sampling system using a combination of a balloon and a gliding UAV was developed in order to retrieve observation apparatuses and aerosol samples easily at low cost. A feasibility study was performed by a point mass simulation, and the UAV named Phoenix was built. Since the whole system has to be exposed in a very low temperature environment for a couple of hours, thermal insulation especially for avionics and servo motors was implemented and tested. The response delay of servo motors was observed by the test, and the effect of response delay on control together with air density reduction at higher altitude was confirmed to be relatively small in a $6 \mathrm{DOF}$ simulation. Five observation flights were conducted in January 2013 at Syowa Station in Antarctica, and all aerosol observation and sampling were successfully performed as planned up to $10,000 \mathrm{~m}$ in altitude. Five times of observations and sample returns without losing any observation apparatuses in only one month is significant, and this method will contribute to atmospheric science in Antarctica. The authors are planning to increase separation altitude up to 20 to $30 \mathrm{~km}$ which is comparable to the maximum altitude of the free balloon observation method as the future work.

\section{Acknowledgments}

We would like to thank the all members of 54th Japan Antarctic Research Expedition (JARE54) and wintering members of 53rd JARE for their cooperation in the flight operations, all members of the icebreaker "Shirase" in the transportation, supporting member of Antarctic Observation Center, Mr. Matsubara, Mr. Nagayasu, Mr. Kinjyo, and Mr. Hirakawa of Kyushu University in making the UAV avionics and parts, Mr. Rattanarrom of $\mathrm{X}$-Treme Composite Thailand for building the UAVs, students in the labs of Kyushu University and Fukuoka University for flight testing, Mr. Yamashita of Flying High Sky Sports Club, Mr. Ino of Aso Kankobokujyo airfield, Mr. Yagyu of Matsuyamanojyo, and information officers of JCAB and JASDF for domestic flight tests. This research is funded by Observation Program AP11 and AP14 of NIPR, Grant-in-Aid for Scientific Research (KAKENHI 23651019, 2011-2014 and KAKENHI 24403001, 2012-2015).

\section{References}

1) Dias, N. L., Gonçalves, J. E., Freire, L. S., Hasegawa, T. and Malheiros, A. L. : Obtaining Potential Virtual Temperature Profiles, Entrainment Fluxes, and Spectra from Mini Unmanned Aerial Vehicle Data, Boundary-Layer Meteorology, 145, 1(2012), pp.93-111.

2) Curry, J. A., Maslanik, J. M. and Pinto, J. O. : Aerosonde Operations in the Arctic, AIAA-2002-3403, 2002.

3) Van den Kroonenberg, A. C. : Bondary Layer Measurements with the Autonomous Mini-UAVM2AV, Proceedings of DACH2007, Hamburg, Germany, 2007.

4) Funaki, M., Hirasawa, N. and Ant-Plane Group: Outline of a Small Unmanned Aerial Vehicle (Ant-Plane) Designed for Antarctic Research, Polar Science, 2(2008), pp.129-142.

5) Burkhart, J. F., Storvold, R., Pedersen, C., Bogren, W., Bates, T. and Quinn, P.: Addressing Black Carbon Driven Albedo Variability in the Arctic : VAUUAV, Proceedings of the International Polar Year Oslo Science Conference, 2010.

6) Higashino, S., Funaki, M., Hirasawa, N., Hayashi, M. and Nagasaki, S. : Development and Operational Experiences of UAVs for Scientific Research in Antarctica, Autonomous Control Systems and Vehicles, International Series on Intelligent Systems, Control and Automation : Science and Engineering, Vol.65, Springer, 2013, pp.159-173.

7) Higashino, S. : Development of an UAV Flight Control Module for the Operation in Antarctica, The 5th Asian-Pacific Conference on Aerospace Technology and Science, 2006,CD-ROM.

8) University of Wyoming, Atmospheric Soundings. http://weather.uwyo.edu/upperair/sounding.html

9) Kozai, S., Yamamoto, R., Higashino, S., Hayashi, M. : A Study on a Balloon-Separated Autonomous Return UAS for Atmospheric Observations, Proceedings of 46th Aircraft Symposium, 2008, CD-ROM (In Japanese).

10) University Corporation for Atmospheric Research (UCAR), The Antarctic Mesoscale Prediction System (AMPS). http://www.mmm.ucar.edu/rt/amps/

11) University of Wyoming, Balloon Trajectory Forecasts. http://weather.uwyo.edu/polar/balloon_traj.html 